\title{
Annular MHD Physics for Turbojet Energy Bypass
}

Steven J. Schneider

Glenn Research Center, Cleveland, Ohio 


\section{NASA STI Program . . . in Profile}

Since its founding, NASA has been dedicated to the advancement of aeronautics and space science. The NASA Scientific and Technical Information (STI) program plays a key part in helping NASA maintain this important role.

The NASA STI Program operates under the auspices of the Agency Chief Information Officer. It collects, organizes, provides for archiving, and disseminates NASA's STI. The NASA STI program provides access to the NASA Aeronautics and Space Database and its public interface, the NASA Technical Reports Server, thus providing one of the largest collections of aeronautical and space science STI in the world. Results are published in both non-NASA channels and by NASA in the NASA STI Report Series, which includes the following report types:

- TECHNICAL PUBLICATION. Reports of completed research or a major significant phase of research that present the results of NASA programs and include extensive data or theoretical analysis. Includes compilations of significant scientific and technical data and information deemed to be of continuing reference value. NASA counterpart of peer-reviewed formal professional papers but has less stringent limitations on manuscript length and extent of graphic presentations.

- TECHNICAL MEMORANDUM. Scientific and technical findings that are preliminary or of specialized interest, e.g., quick release reports, working papers, and bibliographies that contain minimal annotation. Does not contain extensive analysis.

- CONTRACTOR REPORT. Scientific and technical findings by NASA-sponsored contractors and grantees.
- CONFERENCE PUBLICATION. Collected papers from scientific and technical conferences, symposia, seminars, or other meetings sponsored or cosponsored by NASA.

- SPECIAL PUBLICATION. Scientific, technical, or historical information from NASA programs, projects, and missions, often concerned with subjects having substantial public interest.

- TECHNICAL TRANSLATION. Englishlanguage translations of foreign scientific and technical material pertinent to NASA's mission.

Specialized services also include creating custom thesauri, building customized databases, organizing and publishing research results.

For more information about the NASA STI program, see the following:

- Access the NASA STI program home page at http://www.sti.nasa.gov

- E-mail your question via the Internet to help@ sti.nasa.gov

- Fax your question to the NASA STI Help Desk at $443-757-5803$

- Telephone the NASA STI Help Desk at 443-757-5802

- Write to: NASA Center for AeroSpace Information (CASI) 7115 Standard Drive Hanover, MD 21076-1320 


\section{Annular MHD Physics for Turbojet Energy Bypass}

Steven J. Schneider

Glenn Research Center, Cleveland, Ohio

Prepared for the

17th International Space Planes and Hypersonic Systems and Technologies Conference sponsored by the American Institute of Aeronautics and Astronautics San Francisco, California April 11-14, 2011

National Aeronautics and

Space Administration

Glenn Research Center

Cleveland, Ohio 44135 


\section{Acknowledgments}

The author wishes to acknowledge many fruitful discussions with Dr. Isaiah Blankson during this analysis.

This report contains preliminary findings, subject to revision as analysis proceeds.

Trade names and trademarks are used in this report for identification only. Their usage does not constitute an official endorsement, either expressed or implied, by the National Aeronautics and Space Administration.

Level of Review: This material has been technically reviewed by technical management.

Available from

NASA Center for Aerospace Information 7115 Standard Drive

Hanover, MD 21076-1320
National Technical Information Service 5301 Shawnee Road Alexandria, VA 22312

Available electronically at http://www.sti.nasa.gov 


\title{
Annular MHD Physics for Turbojet Energy Bypass
}

\author{
Steven J. Schneider \\ National Aeronautics and Space Administration \\ Glenn Research Center \\ Cleveland, Ohio 44135
}

\begin{abstract}
The use of annular Hall type MHD generator/accelerator ducts for turbojet energy bypass is evaluated assuming weakly ionized flows obtained from pulsed nanosecond discharges. The equations for a 1-D, axisymmetric MHD generator/accelerator are derived and numerically integrated to determine the generator/accelerator performance characteristics. The concept offers a shockless means of interacting with high speed inlet flows and potentially offers variable inlet geometry performance without the complexity of moving parts simply by varying the generator loading parameter. The cycle analysis conducted iteratively with a spike inlet and turbojet flying at $\mathrm{M}=7$ at $30 \mathrm{~km}$ altitude is estimated to have a positive thrust per unit mass flow of $185 \mathrm{~N}-\mathrm{s} / \mathrm{kg}$. The turbojet allowable combustor temperature is set at an aggressive $2200^{\circ} \mathrm{K}$. The annular MHD Hall generator/accelerator is $\mathrm{L}=3 \mathrm{~m}$ in length with a $\mathrm{B}_{\mathrm{r}}=5$ Tesla magnetic field and a conductivity of $\sigma=5 \mathrm{mho} / \mathrm{m}$ for the generator and $\sigma=1.0 \mathrm{mho} / \mathrm{m}$ for the accelerator. The calculated isentropic efficiency for the generator is $\eta_{\mathrm{sg}}=84$ percent at an enthalpy extraction ratio, $\eta_{\mathrm{Ng}}=0.63$. The calculated isentropic efficiency for the accelerator is $\eta_{\mathrm{sa}}=81$ percent at an enthalpy addition ratio, $\eta_{\mathrm{Na}}=0.62$. An assessment of the ionization fraction necessary to achieve a conductivity of $\sigma=1.0 \mathrm{mho} / \mathrm{m}$ is $n_{e} / \mathrm{n}=1.90 \times 10^{-6}$, and for $\sigma=5.0 \mathrm{mho} / \mathrm{m}$ is $n_{e} / \mathrm{n}=9.52 \times 10^{-6}$.
\end{abstract}

\section{Nomenclature}

$\begin{array}{ll}A & \text { flow area normal to } z \text { axis } \\ \mathbf{B} & \text { vector magnetic field } \\ \mathrm{B}_{\theta} & \text { tangential magnetic field } \\ \mathrm{B}_{\mathrm{r}} & \text { radial magnetic field } \\ \mathrm{B}_{\mathrm{z}} & \text { axial magnetic field } \\ \mathrm{c}_{\mathrm{e}} & \text { mean random thermal velocity of the electrons } \\ \mathrm{C}_{\mathrm{p}} & \text { specific heat at constant pressure of air } \\ \mathbf{E} & \text { vector of applied electric field } \\ \mathrm{e} & \text { magnitude of electron charge } \\ \mathrm{E}_{\theta} & \text { tangential applied electric field } \\ \mathrm{E}_{\mathrm{r}} & \text { radial applied electric field } \\ \mathrm{E}_{\mathrm{z}} & \text { axial applied electric field } \\ \mathrm{h} & \text { enthalpy per unit mass of gas } \\ \mathrm{I} & \text { current } \\ \mathbf{j} & \text { vector current density } \\ \mathrm{j}_{\theta} & \text { tangential current density } \\ \mathrm{j}_{\mathrm{r}} & \text { radial current density } \\ \mathrm{j}_{z} & \text { axial current density } \\ \mathrm{k} & \text { Boltzmann's constant } \\ \mathrm{K}_{\mathrm{h}} & \text { MHD generator-accelerator Hall loading parameter } \\ \dot{\mathrm{m}} & \text { mass flow } \\ \mathrm{m}_{\mathrm{e}} & \text { mass of an electron } \\ \mathrm{MHD} & \text { Magnetohydrodynamics } \\ \mathrm{n} & \text { number density of atoms or molecules in the flow }\end{array}$




$\begin{array}{ll}n_{e} & \text { electron number density in the flow } \\ \mathrm{P}_{\mathrm{e}} & \text { Electrical power } \\ \mathrm{P}_{\mathrm{o}} & \text { total pressure of flow } \\ \mathrm{P}_{\mathrm{s}} & \text { static pressure of flow } \\ \mathrm{Q} & \text { electron-molecule momentum transfer cross section } \\ \mathrm{R} & \text { gas constant of air } \\ \mathrm{r} & \text { radial coordinate of flow } \\ \mathrm{S} & \text { entropy } \\ \mathrm{T}_{\mathrm{e}} & \text { electron temperature } \\ \mathrm{T}_{\mathrm{o}} & \text { total temperature of flow } \\ \mathrm{U} & \text { internal energy of gas } \\ V & \text { Hall voltage across generator or accelerator, integral of } \mathrm{E}_{\mathrm{Z}} \mathrm{dz} \\ \mathbf{V} & \text { vector velocity of flow } \\ \mathrm{V}_{\theta} & \text { tangential velocity of flow } \\ \mathrm{V}_{\mathrm{r}} & \text { radial velocity of flow } \\ \mathrm{V}_{\mathrm{z}} & \text { axial velocity of flow } \\ \omega \tau & \text { Hall parameter } \\ \mathrm{Z} & \text { axial coordinate, axis of symmetry of flow } \\ \alpha & \text { fraction of discharge energy going into Joule heating of the flow } \\ \eta_{\mathrm{Na}} & \text { enthalpy addition ratio of accelerator } \\ \eta_{\mathrm{Ng}} & \text { enthalpy extraction ratio of generator } \\ \eta_{\mathrm{sa}} & \text { isentropic efficiency of accelerator } \\ \eta_{\mathrm{sg}} & \text { isentropic efficiency of generator } \\ \theta & \text { tangential coordinate of flow } \\ \rho & \text { density of gas } \\ \sigma & \text { electrical conductivity } \\ & \end{array}$

\section{Introduction}

The Russian AJAX hypersonic vehicle was the first to propose magnetohydrodynamic (MHD) energy bypass of a scramjet as a means of extending the scramjet's performance to higher mach numbers (Ref. 1). Analyses of the concept lead to the conclusion that energy bypass of a scramjet can result in subsonic ramjet propulsion being maintained in the Mach No. 10 to 16 speed range (Ref. 2). A simplified thermodynamic cycle analysis of scramjet energy bypass demonstrated that the concept merits further investigation (Ref. 3). Based on these results, an examination of the feasibility of MHD energy bypass with turbojets was proposed (Ref. 4). As with the scramjet, the enthalpy into the combustor is to be reduced allowing more efficient addition of energy in the combustor without exceeding temperature limitations on the turbine materials. Preliminary 1-D analysis of the energy extraction process shows that significant enthalpy extraction is possible, but this extraction also results in significant total pressure losses (Ref. 5). The annular MHD Hall generator concept was proposed for geometric compatibility with the turbojet (Ref. 6). This geometry was successfully applied to in-space propulsion engine by the Russians with their Stationary Plasma Thruster using very low pressure xenon plasmas and is flying on the Russian Express satellite (Ref. 7). The geometry was also previously explored for stationary combustion driven MHD power generation in the 1950s (Ref. 8). A concept vehicle showing power generation and distribution is shown in Figure 1. These efforts are motivated by a need to develop a single flow path solution to a Mach 7 air breathing engine without the need for mode transitions.

Besides NASA's traditional use of plasmas in space thrusters (Refs. 9 and 10), there is a growing interest in plasma-based aerodynamics, including flow manipulation through MHD forces, power generation, drag reduction, and shock mitigation (Refs. 11 to 14). The goal of this paper is to examine the 


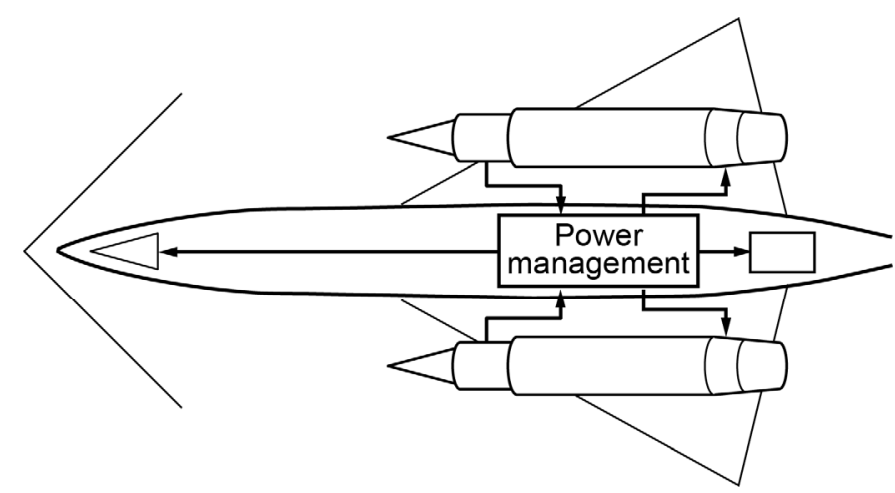

Figure 1.-Concept vehicle showing MHD energy bypass of a turbojet and potential energy management system.

physics necessary to conduct a 1-D, axisymmetric analysis of an annular MHD generator/accelerator for extracting energy electrically by MHD forces from the flow upstream of a turbojet such that the turbojet can operate within its thermal limits up to a higher Mach number. This electrical energy can be used for vehicle drag reduction or can be reintroduced by MHD acceleration in the nozzle to provide positive thrust to the vehicle at the higher Mach number. An important goal is to determine whether nonequilibrium ionization efficiently generated in a supersonic flow using pulsed nanosecond discharges (Ref. 15) can be used to produce a Lorentz force of a magnitude sufficient to generate substantial amounts of electrical power, and to considerably reduce the kinetic energy of the flow. Nonequilibrium ionization is believed to be a key factor in this analysis, since the customarily introduced alkali metals are corrosive to super alloys.

The term "plasma" is used to describe a fourth state of matter along with solids, liquids, and gases. One usually thinks of them as a high temperature "fully ionized" medium, but the definition of "plasmas" is extended to the "partially ionized" gases of interest in this analysis. The most important difference between "ionized" and "ordinary" gases is that they can be acted upon by electromagnetic forces. The chosen method of analytical treatment called "plasma dynamics" is to define the macroscopic properties of the plasma using the theory of the "continuum". We postulate the macroscopic properties by considering the conservation laws of mass, momentum, energy, and charge. In general, however, the plasma should be considered as a mixture of ions, electrons, and neutral particles that is neutral overall and the "kinetic theory of plasmas" should be applied. The ions and electrons continually experience MHD forces which accelerate their motion. All of the particles suffer collisions and the forces acting on the ions and electrons are transmitted to the neutrals by collisions thus becoming forces acting on the gas as a whole. It is left to future work to investigate the relationship between these two approaches.

\section{Generalized 3-D MHD Equations}

The fundamental equations of "plasma dynamics" have been greatly simplified by the MHD approximation (Ref. 16) which uses the assumptions given below. The assumptions that went into these simplified equations (Ref. 17) have been tested experimentally and found to be valid in the Department of Energy's MHD power generation program (Ref. 18) of the 1970s and 1980s. These assumptions are:

1. The plasma is a single continuous medium of definite composition

2. Electromagnetic forces are of the same order as gas dynamic forces

3. The time scale of the problem is the characteristic length divided by a characteristic velocity.

4. The applied electric field $\mathbf{E}$ is of the same order as the induced electromotive force.

5. The flow velocity is much smaller than the speed of light. 
6. Maxwell's equations are unaffected by the gasdynamic motion or, in other words, the magnetic field induced by the fluid motion is small compared to the applied magnetic field

7. Invicid flow is assumed, but a friction term can be easily added to the momentum equation.

8. No heat loss is assumed, but a heat loss term can be easily added to the energy equation.

9. The equation of state of the gas is assumed to be the perfect gas law, but other equations of state can be implemented.

10. Body forces due to gravity are neglected

11. Steady state is assumed

These simplified 3-D equations (Ref. 17) are as follows:

Momentum:

Mass:

$$
\rho(\mathbf{v} \cdot \nabla) \mathbf{v}=\mathbf{j} \times \mathrm{B}-\nabla \mathrm{p}
$$

$$
\nabla \cdot(\rho \mathbf{v})=0
$$

Energy:

$$
\rho \mathbf{v} \cdot \nabla\left(\frac{|v|^{2}}{2}+U\right)=-\nabla \cdot(\mathbf{v p})+\mathbf{j} \cdot E
$$

Current:

$$
\boldsymbol{\nabla} \cdot \mathrm{j}=0
$$

Ohm's Law:

$$
j=\sigma(E+v \times B)-\frac{\omega \tau}{|B|} j \times B
$$

\section{Axisymmetric 1-D MHD Equations}

The above simplified 3-D equations are reduced to a 1-D axisymmetric form for the annular geometry and coordinate system shown in Figure 2 and using the following assumptions. This is similar to a mean line flow calculation in a turbomachine.

1. Azimuthal symmetry

2. Large radius approximation, with functions of $z$ only: $p(z), v_{\theta}(z), v_{z}(z), j_{\theta}(z), j_{z}(z), T(z), \rho(z)$, $\mathrm{E}_{\mathrm{z}}(\mathrm{z})$

3. Constant terms: $B_{r}, \sigma$

4. Zero terms: $B_{\theta}, B_{z}, v_{r}, j_{r}, E_{\theta}, E_{r}$

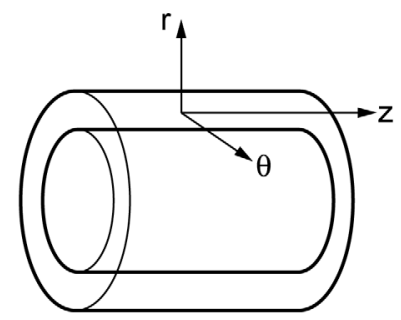

Figure 2.-Annular geometry and coordinate system. 
Axial Momentum:

Angular Momentum:

$$
\rho v_{z} \frac{d v_{z}}{d z}=-j_{\theta} B_{r}-\frac{d p}{d z}
$$

Axial Ohm's Law:

$$
\rho v_{\mathrm{z}} \frac{\mathrm{dv}_{\theta}}{\mathrm{dz}}=\mathrm{j}_{\mathrm{z}} B_{\mathrm{r}}
$$

Angular Ohm's Law:

$$
\mathrm{j}_{\mathrm{z}}=\frac{\sigma \mathrm{B}_{\mathrm{r}}}{1+(\omega \tau)^{2}}\left[\frac{\mathrm{E}_{\mathrm{z}}}{\mathrm{B}_{\mathrm{r}}}-\mathrm{v}_{\theta}+\frac{\omega \tau \mathrm{B}_{\mathrm{r}}}{|\mathrm{B}|} \mathrm{v}_{\mathrm{z}}\right]
$$

$$
\mathrm{j}_{\theta}=\frac{\sigma \mathrm{B}_{\mathrm{r}}}{1+(\omega \tau)^{2}}\left[\mathrm{v}_{\mathrm{z}}-\omega \tau \frac{\mathrm{E}_{\mathrm{z}}}{|\mathrm{B}|}+\frac{\omega \tau \mathrm{B}_{\mathrm{r}}}{|\mathrm{B}|} \mathrm{v}_{\theta}\right]
$$

Energy:

$$
\rho v_{\mathrm{z}} \frac{\mathrm{d}}{\mathrm{dz}}\left(\frac{\mathrm{v}_{\theta}^{2}+\mathrm{v}_{\mathrm{z}}^{2}}{2}+\mathrm{h}\right)=\mathrm{j}_{\mathrm{z}} \mathrm{E}_{\mathrm{z}}
$$

Continuity:

Conservation of Current:

$$
\rho v_{z} A=\dot{m}
$$

Electrical power:

$$
\mathrm{j}_{\mathrm{z}} \mathrm{A}=\mathrm{I}
$$

Ideal gas equation of state:

$$
\mathrm{P}_{\mathrm{e}}=\mathrm{IV}
$$

Calorically perfect gas:

$$
\rho=\frac{\mathrm{P}_{\mathrm{s}}}{\mathrm{RT}_{\mathrm{s}}}
$$

Entropy of perfect gas:

$$
\mathrm{C}_{\mathrm{p}} \mathrm{T}_{\mathrm{o}}=\mathrm{C}_{\mathrm{p}} \mathrm{T}_{\mathrm{s}}+\frac{\mathrm{v}_{\mathrm{z}}^{2}}{2}+\frac{\mathrm{v}_{\theta}^{2}}{2}
$$

$$
\mathrm{dS}=\mathrm{C}_{\mathrm{p}} \frac{\mathrm{dT}_{\mathrm{o}}}{\mathrm{T}_{\mathrm{o}}}-\mathrm{R} \frac{\mathrm{dP}_{\mathrm{o}}}{\mathrm{P}_{\mathrm{o}}}
$$

\section{1-D Annular MHD Calculation Procedure}

The above axisymmetric 1-D equations describe a pure Hall type device, since the applied tangential electrical field $E_{\theta}$ is zero by short circuit around the annulus. In order to numerically evaluate these equations, the Hall parameter $\omega \tau$ is related to macroscopic properties of the plasma. The following definition is used

$$
\omega \tau=\frac{\mathrm{e}|\mathrm{B}|}{\mathrm{m}_{\mathrm{e}} \mathrm{nQc} \mathrm{e}_{\mathrm{e}}}
$$

Here we use a two temperature model of the plasma where the electron temperature $T_{e}$ is much higher than the bulk gas static temperature $\mathrm{T}_{\mathrm{s}}$. Such nonequilibrium plasmas can be generated experimentally in high speed flows using high voltage pulsed nanosecond discharges (Ref. 19). Numerical modeling of such discharges places the electron temperature at $\mathrm{T}_{\mathrm{e}}=1 \mathrm{ev}$, i.e., $\mathrm{T}_{\mathrm{e}}=11605^{\circ} \mathrm{K}$ (Ref. 20). The mean random thermal velocity of the electrons, $c_{e}$ is calculated to be $c_{e}=6.692 \times 10^{7} \mathrm{~cm} / \mathrm{sec}$ from

$$
\mathrm{c}_{\mathrm{e}}=\sqrt{\frac{8 \mathrm{kT} \mathrm{T}_{\mathrm{e}}}{\pi \mathrm{m}_{\mathrm{e}}}}
$$

The electron-molecule momentum transfer cross section for air is estimated (Ref. 17) to be $\mathrm{Q}=8 \times 10^{-16} \mathrm{~cm}^{2}$. The number density $\mathrm{n}$ for air at the local static pressure $\mathrm{P}_{\mathrm{s}}$ and local static temperature 
$\mathrm{T}_{\mathrm{s}}$ is found from the Loschmidt Number of $2.69 \times 10^{19}$ molecules $/ \mathrm{cm}^{3}$ at standard temperature and pressure.

The externally applied electric field $\mathrm{E}_{\mathrm{z}}$ is defined using the Hall loading parameter $\mathrm{K}_{\mathrm{h}}$ as follows:

$$
\mathrm{K}_{\mathrm{h}}=\frac{\propto \mathrm{E}_{\mathrm{z}}}{\omega \tau v_{\mathrm{z}} \mathrm{B}_{\mathrm{r}}}
$$

where $\alpha$ is the fraction of discharge energy going into Joule heating of the gas. This number has been shown to be as low as 0.02 in electrical discharges in nitrogen (Ref. 21). The rest of the discharge energy fraction, as high as 0.98 , goes into vibrational excitation of the gas and is trapped inside the vibrational states of the molecules. As such, it does not contribute to the bulk gas translational temperature which also determines entropy rise. The relevant $\alpha$ depends strongly on the gas composition and is especially sensitive to the presence of water molecules. Experimental measurements (Ref. 19) indicate that $\alpha=0.1$ in dry air and rises to $\alpha=0.4$ in moist air. The $\alpha$ in combustion products can be expected to be even higher. Energy deposited in vibrational states of molecules is known to have relaxation times on the order of milliseconds (Ref. 22), which may be enough time to transit the MHD generator and accelerator and affect their performance, but probably not enough time to transit the entire cycle. This effect of $\alpha$ has not been considered in the calculations presented in this paper, i.e., the assumed $\alpha=1.0$.

One of the goals of this analysis is to determine the magnitudes of the electrical conductivity, magnetic field, and length of flow path that are required for the enthalpy extraction and addition operations. These parameters are therefore inputs to the calculation. In order to solve the above set of equations, ((6) to (19)), one more parameter such as the flow area must be specified. It was found to facilitate the numerical analysis to specify

$$
\frac{\mathrm{d}\left(\rho \mathrm{v}_{\mathrm{z}}\right)}{\mathrm{dz}}=\text { constant }
$$

instead of specifying the flow geometry. An annular Hall generator/accelerator concept is shown in Figure 3 where the ionized flow in the annulus interacts with a vector current $\mathbf{j}$ composed of components $j_{z}$ and $j_{\theta}$ which forms a spiral in the annulus. Electrodes providing the pulsed nanosecond discharges for ionization are shown placed at several axial positions to maintain the conductivity and the current $j_{z}$ is withdrawn through the inlet and exit electrodes and flows through the external power extraction/addition circuit.

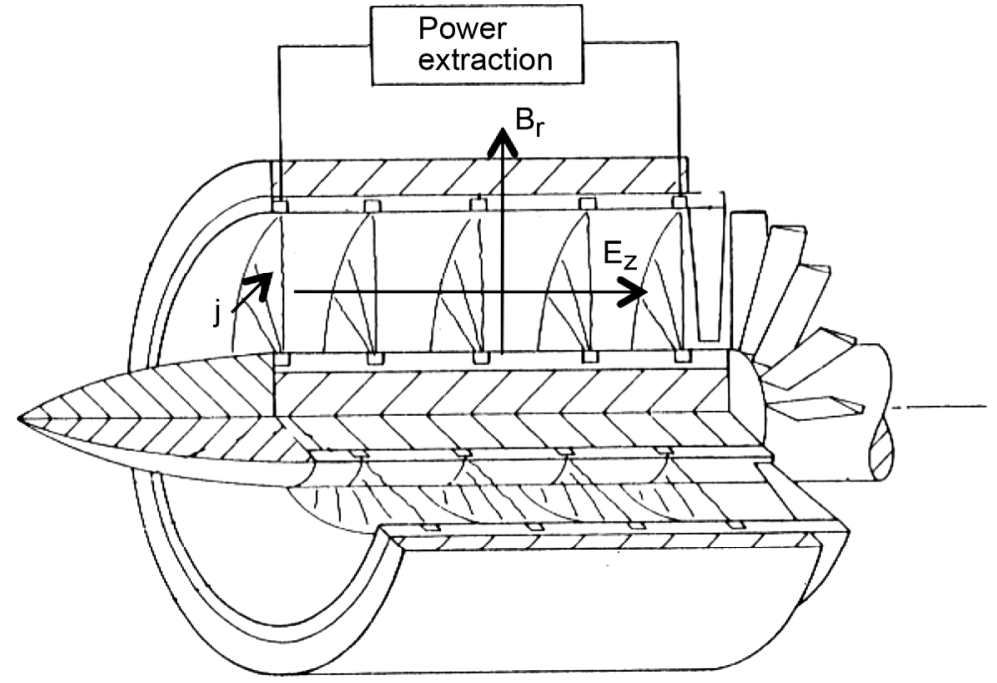

Figure 3.-Annular Hall type MHD power extraction concept for the inlet of a turbojet showing the spiral current path through the annulus. Power addition uses similar geometry at the exit of the turbojet. 


\section{MHD Energy Bypass Turbojet Cycle Analysis}

A preliminary cycle analysis was conducted in order to derive gas dynamic inlet parameters for the MHD generator and accelerator. It was conducted iteratively with the spike inlet and turbojet until a flow path area variation similar to that shown in Figure 4 was attained. A T-s (temperature-entropy) diagram for the cycle flying at $\mathrm{M}=7$ at $30 \mathrm{~km}$ altitude is shown in Figure 5. This cycle is estimated to have a positive thrust per unit mass flow of $185 \mathrm{~N}-\mathrm{s} / \mathrm{kg}$. The turbojet allowable combustor temperature is set at an aggressive $2200{ }^{\circ} \mathrm{K}$. Note that the inlet total temperature of $2453{ }^{\circ} \mathrm{K}$ exceeds this allowable combustor temperature. The MHD generator reduces this total temperature to $930^{\circ} \mathrm{K}$ by extracting $1.6 \mathrm{MW}-\mathrm{s} / \mathrm{kg}$ from the flow. The turbojet at this altitude is estimated to have only a compression ratio of only 1.09 , so only $31 \mathrm{~kW}-\mathrm{s} / \mathrm{kg}$ is transferred from the turbine to the compressor. Heat addition in the combustor raises the total temperature to $2200^{\circ} \mathrm{K}$ and the $1.4 \mathrm{MW}-\mathrm{s} / \mathrm{kg}$ (generator minus ionizer power) energy bypass to the MHD accelerator raises the total temperature of the exit flow to $3633^{\circ} \mathrm{K}$.

The annular MHD Hall generator is $\mathrm{L}=3 \mathrm{~m}$ in length with a $\mathrm{B}_{\mathrm{r}}=5$ Tesla magnetic field, a conductivity $\sigma=5 \mathrm{mho} / \mathrm{m}$ and a loading parameter $\mathrm{K}_{\mathrm{h}}=-0.09$. The derivative of the product $\mathrm{d}\left(\rho \mathrm{v}_{\mathrm{z}}\right) \mathrm{dz}=$ $-21.0 \mathrm{~kg} / \mathrm{m}^{3}$-s is held constant allowing an area variation in the flow path calculation. The Mach number reduction from 5.0 to 2.1 and area variation from 0.013 to $0.086 \mathrm{~m}^{2}-\mathrm{s} / \mathrm{kg}$ in the generator is shown in Figure 6. The total temperature drop from 2530 to $930{ }^{\circ} \mathrm{K}$ is shown in Figure 7 . This corresponds to an enthalpy extraction ratio, $\eta_{\mathrm{Ng}}=0.63$, defined as the ratio of the total enthalpy decrease divided by the inlet total enthalpy. This enthalpy extraction results in two orders of magnitude drop in total pressure Po from 2350 to $18 \mathrm{kPa}$ as shown in Figure 7. This corresponds to an isentropic efficiency of 84 percent. The Hall parameter and axial electric field are given in Figure 8. Keeping the Hall parameter above 20 by maintaining low static pressure is important for the enthalpy extraction process indicating that high altitude operation is preferable. The total voltage across the $3 \mathrm{~m}$ long generator is $\mathrm{V}=55.8 \mathrm{kV}$, i.e., the integral of the axial electric field. Total current flow in the generator is I $=28.7 \mathrm{Amp}-\mathrm{s} / \mathrm{kg}$.

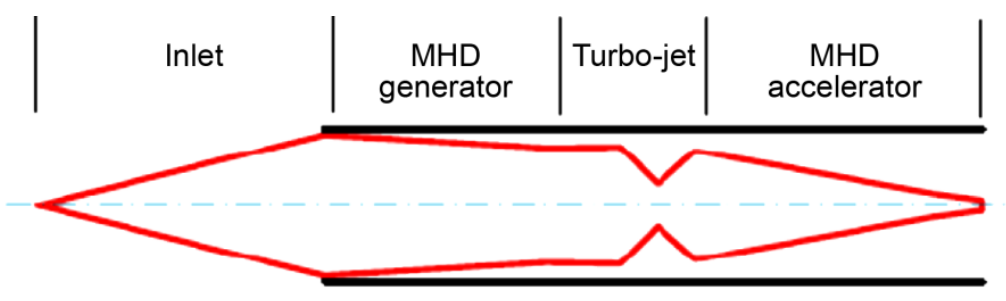

Figure 4.-Concept MHD energy bypass engine flow path with spike inlet followed by the annular MHD generator, turbojet, and annular MHD accelerator.

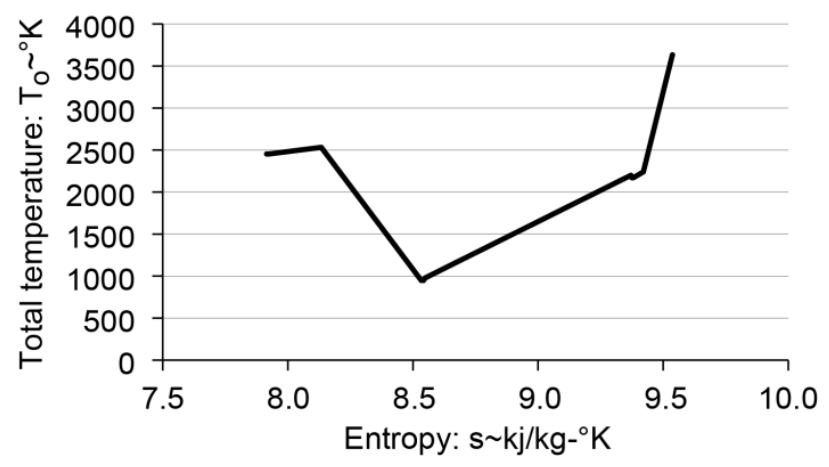

Figure 5.-Total temperature versus entropy for cycle flying at $\mathrm{M}=7$ at $30 \mathrm{~km}$ altitude. 


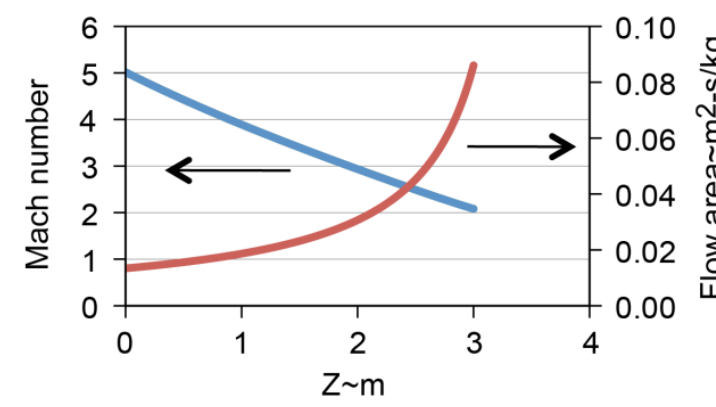

Figure 6.-Mach number and flow area variation in the annular MHD generator.

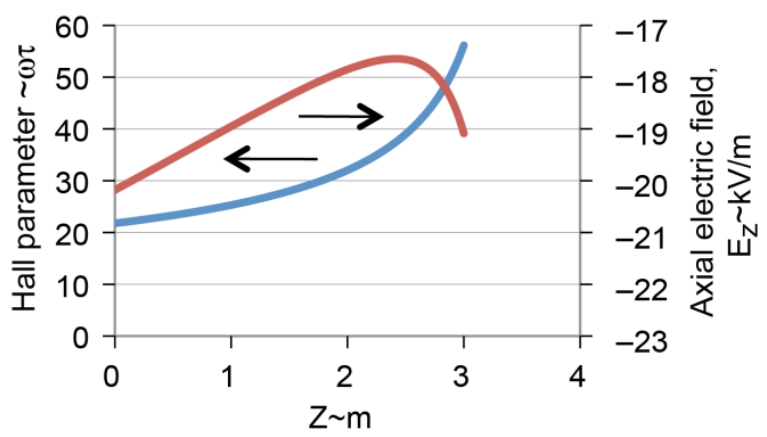

Figure 8.-Hall parameter and axial electric field of annular MHD generator.

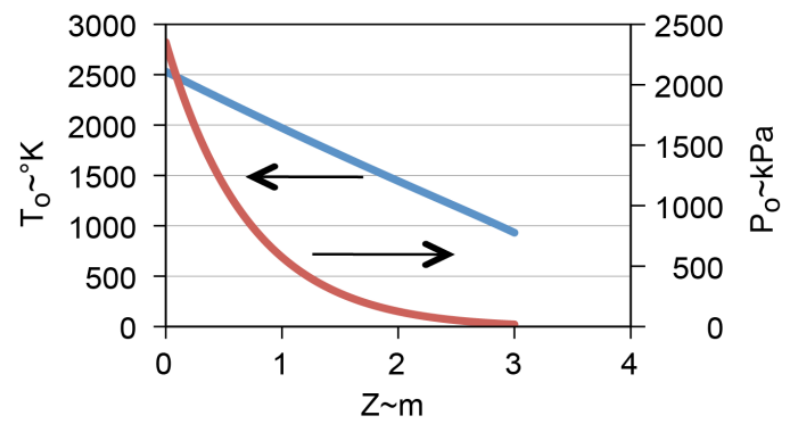

Figure 7.-Total temperature and total pressure drop in the annular MHD generator.

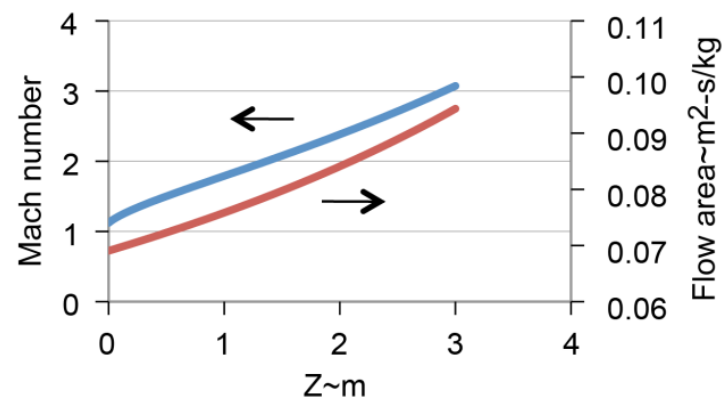

Figure 9.-Mach number and flow area variation in the annular MHD accelerator.

The turbojet is primarily a high altitude combustor since it's compression ratio is only 1.09 . The fuel/air ratio needed to raise the temperature to $2200{ }^{\circ} \mathrm{K}$ in the combustor is 0.0286 using fuel with a heating value of $45000 \mathrm{~kJ} / \mathrm{kg}$. Heat addition in frictionless flow in which the flow area is increased in such a way that static pressure is held constant in the combustor is employed in the analysis.

Following a small expansion downstream of the turbine, the annular MHD accelerator receives the flow at an inlet Mach Number of $\mathrm{M}=1.1$, static pressure $\mathrm{P}_{\mathrm{s}}=58.6$ torr and static temperature $\mathrm{T}_{\mathrm{s}}=1790^{\circ} \mathrm{K}$. Based on these conditions, the inlet Hall parameter $\omega \tau=51.9$. The annular MHD Hall accelerator is $L=3 \mathrm{~m}$ in length with a magnetic field $\mathrm{B}_{\mathrm{r}}=5$ Tesla, a conductivity $\sigma=1.0 \mathrm{mho} / \mathrm{m}$, and a loading parameter $\mathrm{K}_{\mathrm{h}}=0.08$. The derivative of the product $\mathrm{d}\left(\rho \mathrm{v}_{\mathrm{z}}\right) \mathrm{dz}=-1.3 \mathrm{~kg} / \mathrm{m}^{3}-\mathrm{s}$ is held constant allowing an area variation in the flow path calculation. The Mach number increase from 1.1 to 3.1 and area variation from 0.069 to $0.094 \mathrm{~m}^{2}-\mathrm{s} / \mathrm{kg}$ in the accelerator is shown in Figure 9. The total temperature rise from $\mathrm{T}_{\mathrm{o}}=2240$ to $3640{ }^{\circ} \mathrm{K}$ is shown in Figure 10. This corresponds to an enthalpy addition ratio $\eta_{\mathrm{Na}}=0.62$, defined as the ratio of the total enthalpy increase divided by the inlet total enthalpy. This enthalpy addition results in a total pressure rise of Po from 17 to $72 \mathrm{kPa}$ as shown in Figure 10. This corresponds to an isentropic efficiency of 81 percent. The Hall parameter and axial electric field are given in Figure 11. The Hall parameter is above 50 because of the low static pressure and high static temperature enabling the efficient enthalpy addition process. The total voltage across the $3 \mathrm{~m}$ long accelerator is $\mathrm{V}=204.9 \mathrm{kV}$, i.e., the integral of the axial electric field. Total current flow in the accelerator is $\mathrm{I}=6.7 \mathrm{Amp}-\mathrm{s} / \mathrm{kg}$.

Performance maps of generators and accelerators can be derived by solving Equations (6) through (20) for the specified inlet conditions and plotting the exit parameters. When one does this, one finds that exit parameters can be plotted against the combination of parameters $\sigma \mathrm{LB}$, indicating that conductivity $\sigma$, length $\mathrm{L}$, and magnetic field $\mathrm{B}_{\mathrm{r}}$ can be traded off against one another such that the product is constant for the same performance. A plot of generator isentropic efficiency $\eta_{\mathrm{sg}}$ is plotted against $\sigma L B$ for various $\mathrm{K}_{\mathrm{h}}$ in Figure 12 for $\mathrm{d}\left(\rho \mathrm{v}_{\mathrm{z}}\right) / \mathrm{dz}=-21 \mathrm{~kg} / \mathrm{m}^{3}$-s. The operating point at $\eta_{\mathrm{sg}}=0.84$ and $\sigma \mathrm{LB}=75$ on the loading 


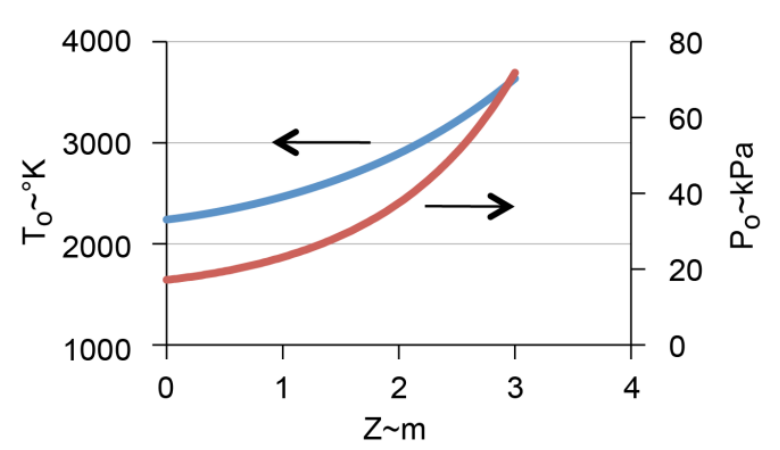

Figure 10.-Total temperature and total pressure rise in the annular MHD accelerator.

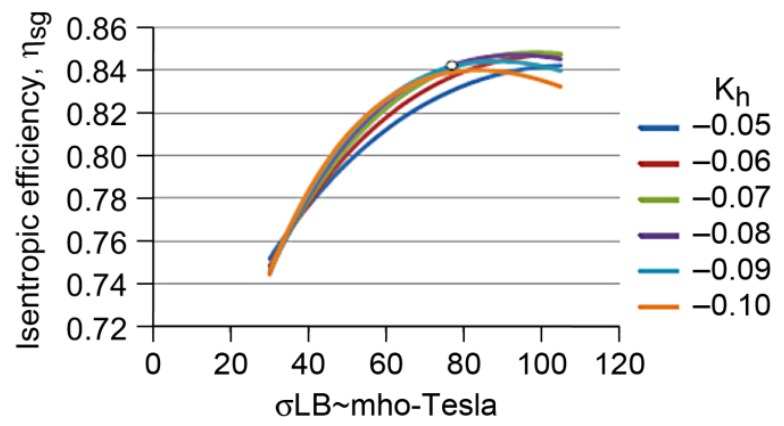

Figure 12.-Isentropic efficiency as a function of MHD generator loading parameter.

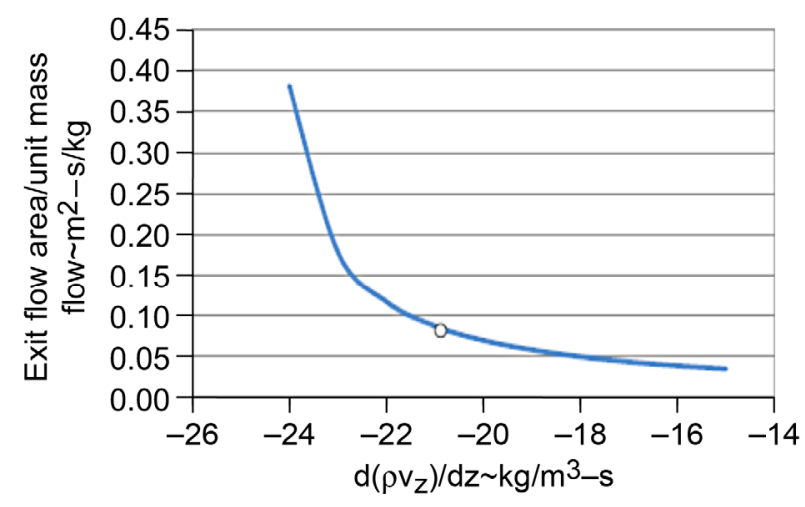

Figure 14.-Exit flow area as a function of $d\left(\rho v_{z}\right) / d z$.

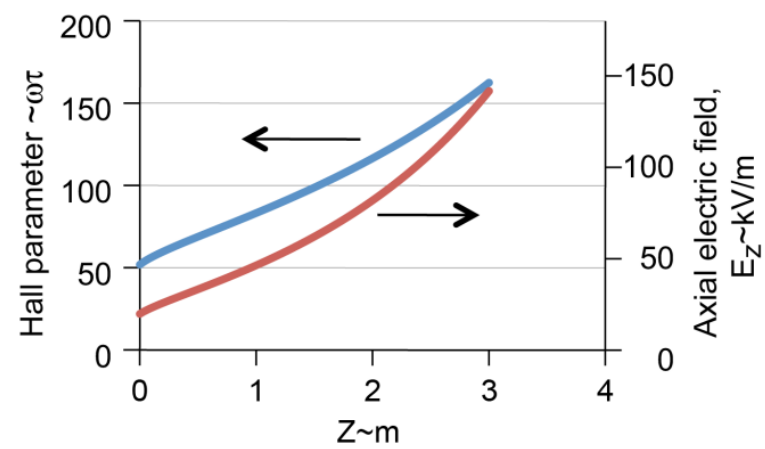

Figure 11.-Hall parameter and axial electric field of annular MHD accelerator.

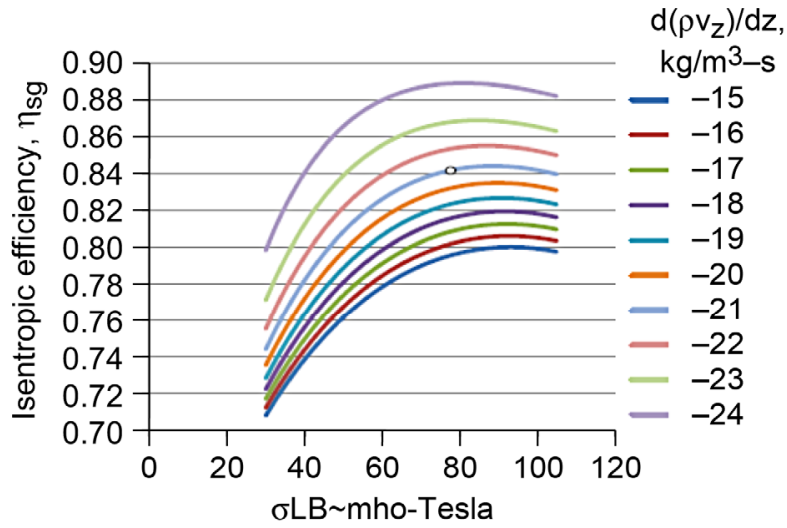

Figure 13.-Isentropic efficiency of the MHD generator as a function of $d\left(\rho v_{z}\right) / d z$.

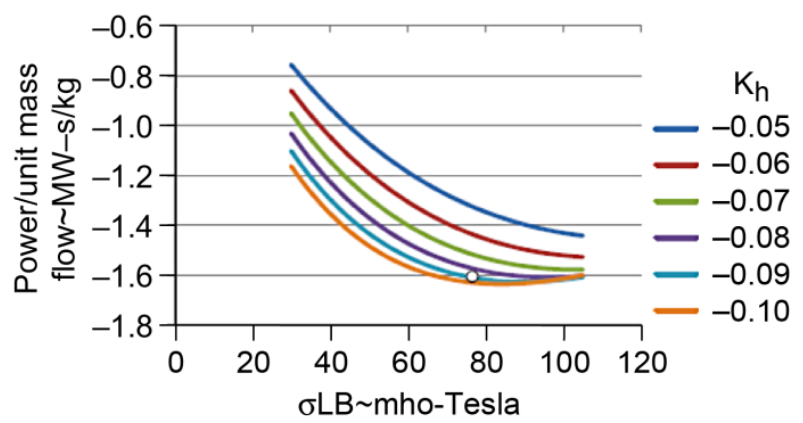

Figure 15.-Generator power per unit mass flow as a function of loading parameter $\mathrm{K}_{\mathrm{h}}$.

curve $K_{h}=-0.09$ is shown by the circle point. Note that there is no higher performance without increasing $\sigma$ or $L$ or $B_{r}$. A similar plot of generator isentropic efficiency $\eta_{\mathrm{sg}}$ is plotted against $\sigma \mathrm{LB}$ for various $\mathrm{d}\left(\rho \mathrm{v}_{\mathrm{z}}\right) / \mathrm{dz}$ in Figure 13 for $\mathrm{K}_{\mathrm{h}}=-0.09$. Again the operating point is shown by the circle point on the $\mathrm{d}\left(\rho \mathrm{v}_{\mathrm{z}}\right) / \mathrm{dz}=-21 \mathrm{~kg} / \mathrm{m}^{3}$-s curve. Note that higher performance is available at more negative $\mathrm{d}\left(\rho \mathrm{v}_{\mathrm{z}}\right) / \mathrm{dz}$, but this performance comes at the expense of increasing exit area as shown on Figure 14. The power generated by the MHD generator is plotted in Figure 15 as a function of $\sigma \mathrm{LB}$ and $\mathrm{K}_{\mathrm{h}}$ for $\mathrm{d}\left(\rho \mathrm{v}_{\mathrm{z}}\right) / \mathrm{dz}$ $=-21 \mathrm{~kg} / \mathrm{m}^{3}-\mathrm{s}$ with the operation point shown at $1.6 \mathrm{MW}-\mathrm{s} / \mathrm{kg}$. This power minus a fraction used in the ionizers is passed on to the MHD accelerator. 


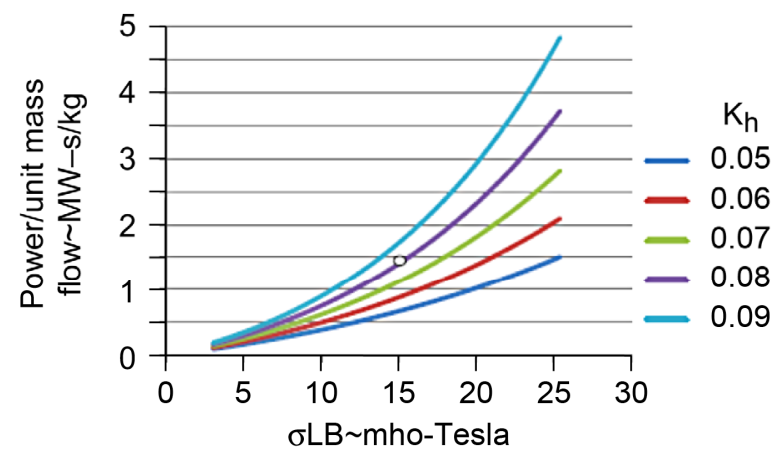

Figure 16.-Accelerator power per unit mass flow as a function of loading parameter $\mathrm{K}_{\mathrm{h}}$.

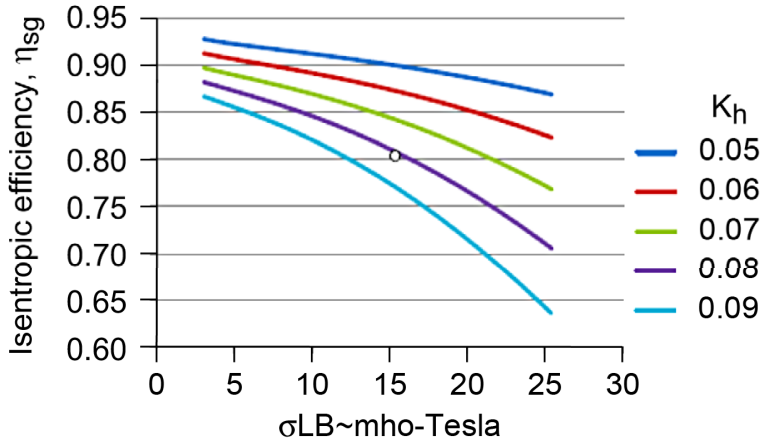

Figure 17.-Isentropic efficiency as a function of MHD accelerator loading parameter.

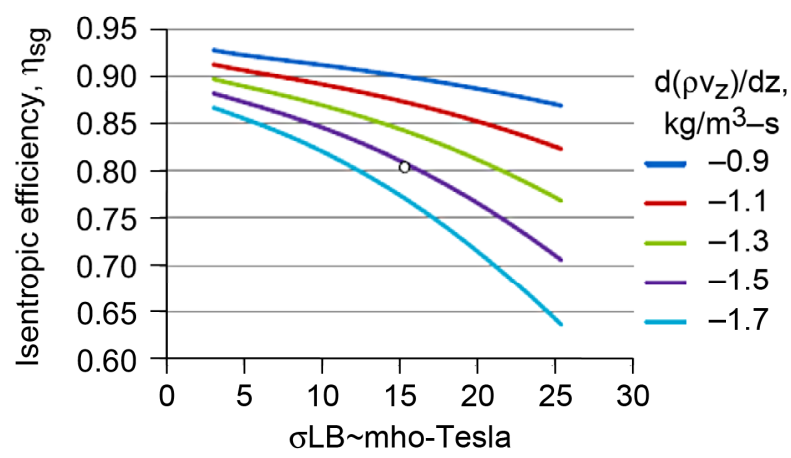

Figure 18.-Isentropic efficiency of the MHD accelerator as a function of $d\left(\rho v_{z}\right) / d z$.

Power used by the accelerator is plotted in Figure 16 as a function of $\sigma \mathrm{LB}$ and $\mathrm{K}_{\mathrm{h}}$ for $\mathrm{d}\left(\rho \mathrm{v}_{\mathrm{z}}\right) / \mathrm{dz}$ $=-1.3 \mathrm{~kg} / \mathrm{m}^{3}$-s with the operating point of $1.4 \mathrm{MW}-\mathrm{s} / \mathrm{kg}$ determined by the power passed to it by the generator. Operation on the $\mathrm{K}_{\mathrm{h}}=0.08$ loading parameter at $\sigma \mathrm{LB}=15$ was chosen. A plot of accelerator isentropic efficiency $\eta_{\mathrm{sa}}$ is plotted against $\sigma \mathrm{LB}$ for various $K_{\mathrm{h}}$ in Figure 17 for $\mathrm{d}\left(\rho \mathrm{v}_{\mathrm{z}}\right) / \mathrm{dz}=-1.3 \mathrm{~kg} / \mathrm{m}^{3}-\mathrm{s}$. The operating point at $\eta_{\mathrm{sg}}=0.81$ and $\sigma \mathrm{LB}=15$ on the loading curve $\mathrm{K}_{\mathrm{h}}=0.08$ is shown by the circle point. Note that higher performance is available at lower $K_{h}$, but higher $\sigma$ or $L$ or $B_{r}$ is required. A similar plot of accelerator isentropic efficiency $\eta_{\text {sa }}$ is plotted against $\sigma L B$ for various $d\left(\rho v_{z}\right) / d z$ in Figure 18 for $\mathrm{K}_{\mathrm{h}}=0.08$. Again the operating point is shown by the circle point on the $\mathrm{d}\left(\rho \mathrm{v}_{\mathrm{z}}\right) / \mathrm{dz}=-1.3 \mathrm{~kg} / \mathrm{m}^{3}-\mathrm{s}$ curve. Note that some higher performance is available for less negative $\mathrm{d}\left(\rho \mathrm{v}_{\mathrm{z}}\right) / \mathrm{dz}$, but this component performance is limited by an expansion to match the exit static pressure at the altitude of flight.

An assessment of the electron number density necessary to achieve the required electrical conductivity is derived from the following equation:

$$
\sigma=\frac{\mathrm{n}_{\mathrm{e}} \mathrm{e}^{2}}{\mathrm{~m}_{\mathrm{e}} \mathrm{nQc} \mathrm{e}}
$$

The ionization fraction, $\mathrm{n}_{\mathrm{e}} / \mathrm{n}$ that results in electrical conductivity $\sigma=1.0 \mathrm{mho} / \mathrm{m}$ can be determined from the equation for $\sigma$. Substituting $\mathrm{Q}=8 \times 10^{-16} \mathrm{~cm}^{2}$ for the estimated electron-molecule momentum transfer cross section for air given previously and $\mathrm{c}_{\mathrm{e}}=6.692 \times 10^{7} \mathrm{~cm} / \mathrm{sec}$ for the mean random thermal velocity of the electrons at an electron temperature of $\mathrm{T}_{\mathrm{e}}=1 \mathrm{ev}$, i.e., $\mathrm{T}_{\mathrm{e}}=11605^{\circ} \mathrm{K}$ (Ref. 20), we get

$$
\sigma=5.25 \times 10^{5} \frac{\mathrm{n}_{\mathrm{e}}}{\mathrm{n}}
$$


For a conductivity of $\sigma=1.0 \mathrm{mho} / \mathrm{m}$ an $\mathrm{n}_{\mathrm{e}} / \mathrm{n}=1.90 \times 10^{-6}$ is required, and for $\sigma=5.0 \mathrm{mho} / \mathrm{m}$ an $\mathrm{n}_{\mathrm{e}} / \mathrm{n}=9.52 \times 10^{-6}$ is required. Ionization fractions were estimated in weakly ionized plasmas using pulsed nanosecond, high-voltage discharges sustained by a lower DC voltage (Ref. 15). The calculations were based on the slope of the DC voltage - current in the sustainer circuit. The reported ionization fractions were relatively constant at $n_{e} / n=1.2 \times 10^{-8}$ over the static pressure range of 10 to 50 torr of interest here. Two to three orders of magnitude higher ionization fraction is required than is currently estimated in the measurements.

\section{Conclusions}

This paper lays a foundation for exploring the thermodynamic benefits of MHD energy bypass in hypersonic propulsion with turbojet engines. The equations for a 1-D, axisymmetric MHD generator/accelerator which can be used in an integrated combined cycle propulsion system analysis incorporating a turbojet are derived and numerically integrated to determine the generator/accelerator performance characteristics. MHD power generation and enthalpy extraction in low-temperature, nonequilibrium supersonic air flows is explored, with the primary application being an MHD inlet diffuser and energy bypass around a turbojet to an MHD accelerator. The annular flowpath geometry of a turbojet suggests the desirability of annular type MHD power extraction/addition devices. The concept offers a shockless means of interacting with high speed inlet flows and potentially offers variable inlet geometry performance without the complexity of moving parts simply by varying the generator loading parameter. The 1-D axisymmetric model of this flow describing the interaction for modeling purposes uses the assumptions/approximations of the more generalized 3-D MHD equations for steady-state flow. A preliminary cycle analysis was conducted in order to derive gas dynamic inlet parameters for the MHD generator and accelerator. It was conducted iteratively with the spike inlet and turbojet flying at $\mathrm{M}=7$ at $30 \mathrm{~km}$ altitude. This cycle is estimated to have a positive thrust per unit mass flow of $185 \mathrm{~N}-\mathrm{s} / \mathrm{kg}$. The turbojet allowable combustor temperature is set at an aggressive $2200{ }^{\circ} \mathrm{K}$. Performance maps of generators and accelerators were derived for the specified inlet conditions. It was found that exit parameters can be plotted against the combination of parameters $\sigma \mathrm{LB}$, indicating that conductivity $\sigma$, length $\mathrm{L}$, and magnetic field $\mathrm{B}$ can be traded off against one another such that the product is constant for the same performance. The annular MHD Hall generator is $L=3 \mathrm{~m}$ in length with a $\mathrm{B}_{\mathrm{r}}=5$ Tesla magnetic field and a conductivity of $\sigma=5 \mathrm{mho} / \mathrm{m}$. The Mach number reduction is from 5.0 to 2.1 and area variation is from 0.013 to $0.086 \mathrm{~m}^{2}-\mathrm{s} / \mathrm{kg}$ in the generator. The total temperature drop from 2530 to $930^{\circ} \mathrm{K}$. This corresponds to an enthalpy extraction ratio, $\eta_{\mathrm{Ng}}=0.63$. This enthalpy extraction results in two orders of magnitude drop in total pressure Po from 2350 to $18 \mathrm{kPa}$. This corresponds to an isentropic efficiency of 84 percent. The annular MHD Hall accelerator is $\mathrm{L}=3 \mathrm{~m}$ in length with a magnetic field $\mathrm{B}_{\mathrm{r}}=5$ Tesla and a conductivity $\sigma=1.0 \mathrm{mho} / \mathrm{m}$. The Mach number increase is from 1.1 to 3.1 and area variation is from 0.069 to $0.094 \mathrm{~m}^{2}-\mathrm{s} / \mathrm{kg}$ in the accelerator. The total temperature rise from $\mathrm{T}_{\mathrm{o}}=2240$ to $3640{ }^{\circ} \mathrm{K}$. This corresponds to an enthalpy addition ratio $\eta_{\mathrm{Na}}=0.62$. This enthalpy addition results in a total pressure rise of Po from 17 to $72 \mathrm{kPa}$. This corresponds to an isentropic efficiency of 81 percent. An assessment of the ionization fraction necessary to achieve a conductivity of $\sigma=1.0 \mathrm{mho} / \mathrm{m}$ is $\mathrm{n}_{\mathrm{e}} / \mathrm{n}$ $=1.90 \times 10^{-6}$, and for $\sigma=5.0 \mathrm{mho} / \mathrm{m}$ is $\mathrm{n}_{\mathrm{e}} / \mathrm{n}=9.52 \times 10^{-6}$.

\section{Future Work}

Cycle analysis using this approach should continue with a computational method set up to rapidly establish the performance maps of the generator and accelerator as a function of inlet conditions and control parameters. The method should iterate with the performance of a turbojet to establish and optimize the cycle performance as a function of flight regime. The magnetic field $\mathrm{B}_{\mathrm{r}}$, the load factor $\mathrm{K}_{\mathrm{h}}$, and the conductivity $\sigma$ are all variables that can be varied without any change in geometry. Mass bypass around the turbojet may prove beneficial and can be incorporated with geometric change. The analysis 
should follow the established dynamic pressure corridor of the airframe. Once a 1-D axisymmetric design of a generator and accelerator is established, the large radius approximation should be relaxed going into a 2-D axisymmetric analysis to calculate hub to tip variations in the flow. Finally a full 3-D analysis should be conducted, allowing for 3-D variations in the vectors $\mathbf{B}, \mathbf{E}, \sigma$, and $\mathbf{j}$.

Since the conductivity of the working fluid in the cycle analysis is based on a two temperature gas model with a nonequilibrium ionization process, a higher fidelity analysis should be established in which the plasma is considered as a mixture of ions, electrons, and neutral particles that is neutral overall. This analysis would use the "kinetic theory of plasmas" to follow the relaxation time of the high temperature electrons and the resulting loss of conductivity. The analysis should also look at energy transfer from the electrons into the vibrational states of the neutrals and their subsequent relaxation times.

Experimentally, the pulsed nanosecond discharge method of ionization needs to be developed with the goal of delivering a higher ionization fraction than that currently estimated. Methods of measuring this ionization fraction and the attendant electron temperature distribution function need to be established. Also, methods of measuring the fraction of discharge energy $\alpha$ going into Joule heating of the gas need to be established along with the variability of $\alpha$ as a function of gas composition, especially air with water vapor and carbon dioxide present. Proof of concept generator and accelerator tests need to be designed for wind tunnel testing. These tests should be conducted in parallel with the analysis which would seek to reproduce experimental results analytically.

\section{References}

1. Gurijanov, E.P., and Harsha, P.T.: “AJAX: New Directions in Hypersonic Technology," AIAA-964609, Seventh Aerospace Planes and Hypersonics Technology Conference, Norfolk, VA, 1996.

2. Bruno, C., Czysz, P.A., and Murthy, S.N.B., "Electro-magnetic Interactions in a Hypersonic Propulsion System," AIAA 97-3389, 33rd AIAA/ASME/SAE/ASEE Joint Propulsion Conference, Seattle, WA, July 6-9, 1997.

3. Litchford, R.J., Cole, J.W., Bityurin, V.A., and Lineberry, J.T., "Thermodynamic Cycle Analysis of Magnetohydrodynamic-Bypass Hypersonic Airbreathing Engines,” NASA/TP—2000-210387, July 2000.

4. Murthy, S.N.B. and Blankson, I.M., "MHD Energy Bypass for Turbojet-Based Engines," IAF-00-55-05, 51st International Astronautical Congress, Rio de Janeiro, Brazil, October 2-6, 2000.

5. Adamovich, I.V., Rich, J.W., Schneider, S.J., and Blankson, I.M., "Magnetogasdynamic Power Extraction and Flow Conditioning for a Gas Turbine," AIAA-2003-4289, 34 ${ }^{\text {th }}$ AIAA Plasmadynamics and Lasers Conference, Orlando, FL, June 23-26, 2003.

6. Blankson, I.M. and Schneider, S.J., "Hypersonic Engine Using MHD Energy Bypass with a Conventional Turbojet: A Progress Report," AIAA-2003-6922, $12^{\text {th }}$ AIAA International Space Planes and Hypersonic Systems Conference, Norfolk, VA, December 15-19, 2003.

7. Shumlak, U., Jarboe, T. and Sprenger, R., "Physics of the Hall Thruster," AIAA Paper 97-3048, 33rd AIAA/ASME/SAE/ASEE Joint Propulsion Conference, Seattle, WA, July 6-9, 1997.

8. Karlovitz, B. and Halasz, D., "History of the K and H Generator and Conclusions Drawn from Experimental Results," 3rd Symposium on Engineering Aspects of Magnetohydrodynamics, 1964, pp. 187-203.

9. Schmidt, G.R., Patterson, M.J., and Benson, S.W., "The NASA Evolutionary Xenon Thruster (NEXT): Nasa's Next Step for U.S. Deep Space Propulsion," IAC-08-C4.4.2, $59^{\text {th }}$ International Astronautical Congress, Glasgow, Scotland, UK, Sept. 29 - Oct. 3, 2008.

10. Manzella, D.H., Kamhawi, H., Peterson, P.Y., and Yim, J.T., "Progress on the Development of a Hall Thruster for NASA Science Missions," Proceedings of the Joint Army-Navy-NASA-Air Force (JANNAF) Spacecraft Propulsion Subcommittee (SPS) Meeting; Denver, CO, May 14-17, 2007, Also NASA/TM-2007-215004. 
11. Murray, R.C., Zaidi, S.H., Carraro, M.R., Vasilyak, L., Macheret, S.O., Shneider, M.N., and Miles, R.B., "Investigation of a Mach 3 Cold Air MHD Channel," AIAA-2003-4282, 34 ${ }^{\text {th }}$ AIAA Plasmadynamics and Lasers Conference, Orlando, FL, June 23-26, 2003.

12. Shang, J.S., Kimmel, R., Hayes, J., Tyler, C., and Menart, J., "Hypersonic Experimental Facility for Magnetohydrodynamic Interactions," Journal of Spacecraft and Rockets, Vol. 42, No. 5, SeptemberOctober 2005, pp. 780-789.

13. Nishihara, M., Jiang, N., Rich, J.W., Lempert, W.R., and Adamovich, I.V., "Low-temperature Supersonic Boundary Layer Control Using Repetitively Pulsed Magnetohydrodynamic Forcing," Physics of Fluids 17, 106102, 2005.

14. Bobashev, S.V., Erofeev, A.V., Lapushkina, T.A., Poniaev, S.A., Vasileva, R.V., and Van Wie, D.M., "Effect of Magnetohydrodynamics Interaction in Various Parts of Diffuser on Inlet Shocks: Experiment," Journal of Propulsion and Power, Vol. 21, No. 5, September-October, 2005, pp. 831-837.

15. Schneider, S.J., Kamhawi, H., and Blankson, I.M., "Efficient Ionization Investigation for Flow Control and Energy Extraction," AIAA-2009-1050, 47 ${ }^{\text {th }}$ AIAA Aerospace Sciences Meeting, Orlando, FL, January 5-8, 2009.

16. Pai, Shih-I, Magnetogasdynamics and Plasma Dynamics, Springer-Verlag, Vienna, Prentice-Hall, Inc., Englewood Cliffs, NJ 1962.

17. Rosa, R.J., Magnetohydrodynamic Energy Conversion, McGraw-Hill Book Company, NY, 1968.

18. Chambers, H.F., "Aerospace Applications of the DOE MHD Program Results, Part II: MHD Plasma Physics and Power Generation," AIAA-2008-1389, 46 ${ }^{\text {th }}$ AIAA Aerospace Sciences Meeting, Reno, NV, January 7-10, 2008.

19. Nishihara, M., Rich, J.W., Lempert, W.R. and Adamovich, I.V., "Low-temperature M=3 Flow Deceleration by Lorentz Force," Physics of Fluids 18, 086101, 2006.

20. Nishihara, M. and Adamovich, I.V., "Numerical Simulation of a Crossed Pulser-Sustainer Discharge in Transverse Magnetic Field," IEEE Transactions on Plasma Science, Vol. 35, No. 5, pp. 13121324, October, 2007.

21. Raizer, Y.P., Gas Discharge Physics, Springer-Verlag, Berlin, New York, 1997.

22. Gordiets, B.F., Osipov, A.I., and Shelepin, L.A., Kinetic Processes in Gases and Molecular Lasers, Gordon and Breach Science Publishers, New York, 1988. 


\begin{tabular}{|c|c|c|}
\hline \multicolumn{2}{|c|}{ REPORT DOCUMENTATION PAGE } & $\begin{array}{l}\text { Form Approved } \\
\text { OMB No. 0704-0188 }\end{array}$ \\
\hline \multicolumn{3}{|c|}{ 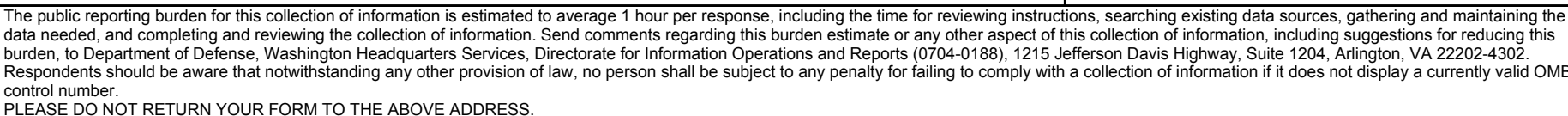 } \\
\hline $\begin{array}{l}\text { 1. REPORT DATE (DD-MM-YYYY) } \\
01-09-2011\end{array}$ & $\begin{array}{l}\text { 2. REPORT TYPE } \\
\text { Technical Memorandum }\end{array}$ & 3. DATES COVERED (From - To) \\
\hline \multirow{3}{*}{\multicolumn{2}{|c|}{$\begin{array}{l}\text { 4. TITLE AND SUBTITLE } \\
\text { Annular MHD Physics for Turbojet Energy Bypass }\end{array}$}} & 5a. CONTRACT NUMBER \\
\hline & & 5b. GRANT NUMBER \\
\hline & & 5c. PROGRAM ELEMENT NUMBER \\
\hline \multirow{3}{*}{\multicolumn{2}{|c|}{$\begin{array}{l}\text { 6. AUTHOR(S) } \\
\text { Schneider, Steven, J. }\end{array}$}} & 5d. PROJECT NUMBER \\
\hline & & 5e. TASK NUMBER \\
\hline & & $\begin{array}{l}\text { 5f. WORK UNIT NUMBER } \\
\text { WBS 599489.02.07.03.07.11.02 }\end{array}$ \\
\hline \multicolumn{2}{|c|}{$\begin{array}{l}\text { 7. PERFORMING ORGANIZATION NAME(S) AND ADDRESS(ES) } \\
\text { National Aeronautics and Space Administration } \\
\text { John H. Glenn Research Center at Lewis Field } \\
\text { Cleveland, Ohio 44135-3191 }\end{array}$} & $\begin{array}{l}\text { 8. PERFORMING ORGANIZATION } \\
\text { REPORT NUMBER } \\
\text { E-17889 }\end{array}$ \\
\hline \multirow{2}{*}{\multicolumn{2}{|c|}{$\begin{array}{l}\text { 9. SPONSORING/MONITORING AGENCY NAME(S) AND ADDRESS(ES) } \\
\text { National Aeronautics and Space Administration } \\
\text { Washington, DC 20546-0001 }\end{array}$}} & $\begin{array}{l}\text { 10. SPONSORING/MONITOR'S } \\
\text { ACRONYM(S) } \\
\text { NASA }\end{array}$ \\
\hline & & $\begin{array}{l}\text { 11. SPONSORING/MONITORING } \\
\text { REPORT NUMBER } \\
\text { NASA/TM-2011-217210 }\end{array}$ \\
\hline \multicolumn{3}{|c|}{$\begin{array}{l}\text { 12. DISTRIBUTION/AVAILABILITY STATEMENT } \\
\text { Unclassified-Unlimited } \\
\text { Subject Categories: } 07,20 \text {, and } 75 \\
\text { Available electronically at http://www.sti.nasa.gov } \\
\text { This publication is available from the NASA Center for AeroSpace Information, 443-757-5802 }\end{array}$} \\
\hline
\end{tabular}

\section{SUPPLEMENTARY NOTES}

\section{ABSTRACT}

The use of annular Hall type MHD generator/accelerator ducts for turbojet energy bypass is evaluated assuming weakly ionized flows obtained from pulsed nanosecond discharges. The equations for a 1-D, axisymmetric MHD generator/accelerator are derived and numerically integrated to determine the generator/accelerator performance characteristics. The concept offers a shockless means of interacting with high speed inlet flows and potentially offers variable inlet geometry performance without the complexity of moving parts simply by varying the generator loading parameter. The cycle analysis conducted iteratively with a spike inlet and turbojet flying at $\mathrm{M}=7$ at $30 \mathrm{~km}$ altitude is estimated to have a positive thrust per unit mass flow of $185 \mathrm{~N}-\mathrm{s} / \mathrm{kg}$. The turbojet allowable combustor temperature is set at an aggressive $2200^{\circ} \mathrm{K}$. The annular MHD Hall generator/accelerator is $\mathrm{L}=3 \mathrm{~m}$ in length with a $\mathrm{B}_{\mathrm{r}}=5$ Tesla magnetic field and a conductivity of $\sigma=5 \mathrm{mho} / \mathrm{m}$ for the generator and $\sigma=1.0 \mathrm{mho} / \mathrm{m}$ for the accelerator. The calculated isentropic efficiency for the generator is $\eta_{\mathrm{sg}}=84$ percent at an enthalpy extraction ratio, $\eta_{\mathrm{Ng}}=0.63$. The calculated isentropic efficiency for the accelerator is $\eta_{\mathrm{sa}}=81$ percent at an enthalpy addition ratio, $\eta_{\mathrm{Na}}=0.62$. An assessment of the ionization fraction necessary to achieve a conductivity of $\eta=1.0 \mathrm{mho} / \mathrm{m}$ is $\mathrm{n}_{\mathrm{e}} / \mathrm{n}$ $=1.90 \times 10^{-6}$, and for $\sigma=5.0 \mathrm{mho} / \mathrm{m}$ is $\mathrm{n}_{\mathrm{e}} / \mathrm{n}=9.52 \times 10^{-6}$.

\section{SUBJECT TERMS}

Magnetohydrodynamics; Plasma-electromagnetic interaction; Hypersonic inlets

\begin{tabular}{|c|c|c|c|c|c|}
\hline \multicolumn{3}{|c|}{ 16. SECURITY CLASSIFICATION OF: } & \multirow{2}{*}{$\begin{array}{l}\text { 17. LIMITATION OF } \\
\text { ABSTRACT } \\
\text { UU }\end{array}$} & \multirow{2}{*}{$\begin{array}{l}\text { 18. NUMBER } \\
\text { OF } \\
\text { PAGES } \\
19\end{array}$} & \multirow{2}{*}{$\begin{array}{l}\text { 19a. NAME OF RESPONSIBLE PERSON } \\
\text { STI Help Desk (email:help@sti.nasa.gov) } \\
\text { 19b. TELEPHONE NUMBER (include area code) } \\
\text { 443-757-5802 }\end{array}$} \\
\hline $\begin{array}{l}\text { a. REPORT } \\
U\end{array}$ & $\begin{array}{l}\text { b. ABSTRACT } \\
U\end{array}$ & $\begin{array}{l}\text { c. THIS } \\
\text { PAGE } \\
\text { U }\end{array}$ & & & \\
\hline
\end{tabular}



